\title{
XXXVIII.-On the Estimation of Silicon in Iron and Steel.
}

\author{
By Thomas Turner, Assoc. R.S.M. (Demonstrator of Chemistry, \\ Mason College).
}

IN connection with an inquiry relating to the influence of silicon in iron and steel, it became of the utmost importance to have some method or methods for the rapid and accurate estimation of silicon in various descriptions of iron and steel. All who have had to do with the analysis of iron are aware that the method of estimation by treatment with hydrochloric acid, with or without subsequent evaporation, though commonly adopted, is quite untrustworthy when the percentage of silicon becomes considerable; and the discrepancies observed in different analyses of highly silicious pig-iron, forcibly illustrate the difficulties of the determination. As my experiments also require the preparation of various alloys of silicon and iron, made by melting together mild steel and silicon iron in small crucibles, it is necessary to be able to distinguish between that part of the total silicon found, which existed probably in combination with the iron, and that which exists in the metal in the oxidised condition in the form of slag.

In connection with a work of this kind, one is forcibly struck with the number of methods which have been proposed at various times by different chemists, and also by the fact that few comparisons of the results obtainable by the different processes have been made. In the endeavour to supply this want of comparison, I have taken different specimens of iron and steel, containing various amounts of silicon up to 9 per cent., and have estimated the amount of silicon, not only by the methods most commonly recommended in text-books, but also by certain processes which seemed to give special promise.

\section{Estimation of Total Silicon.}

I. A quantity of finely divided metal was treated with strong hydrochloric acid until all action ceased; the solution was evaporated to complete dryness on a water-bath; the residue extracted with hydrochloric acid; the solution filtered off; and the residue well washed, dried, ignited to burn off the carbon, and weighed. This treatment gave tolerably rapid and accurate results with steel, or with iron containing not more than 2.5 per cent. silicon, the effect of manganese in altering the results not being appreciable.

With ordinary pig-iron, the method has the disadvantage of yield- 
ing a very bulky residue from which the graphite is not readily burned, and when the percentage of silicon is considerable, it is quite impossible to obtain a pure residue even after boiling with strong hydrochloric acid for many days.

II. The metal was treated with hot strong hydrochloric acid and heated; when all action had ceased, the solution was filtered without evaporation, the residue being washed, dried, and ignited as before. Thongh this method is recommended in certain text-books, probably on account of its rapidity, it has all the disadvantages mentioned in the previous case, and the additional one of leaving part of the silicon in the solution. This fact was mentioned by Drown and Shimer (Chem. News, 42, 299), in a paper on the analysis of iron and steel, in which they prove that " the relative amounts of silicon in solution and in the residue depend on the strength of the acid," less silica being dissolved by a strong than by a weaker acid.

III. The metal was boiled with hydrochloric acid, evaporated to dryness, exhausted with hydrochloric acid, filtered, the residue washed, dried, fused with alkaline fasion mixture, and the silica determined by evaporation to dryness with hydrochloric acid. This method is rather troublesome, but is trustworthy and generally applicable.

IV. The finely divided metal was treated with aqua regia and heated if necessary. The solution was evaporated to dryness on a water-bath, the residue extracted, dried, ignited, and weighed.. In this case, evaporation takes a longer time, but the graphite burns off more readily. The residue obtained is generally coloured from the presence of a little iron, but the results are fairly accurate with moderate percentages of silicon though somewhat high with larger amounts.

V. In the following process, which was originally recommended by Drown (Chem. News, 42, 331), the metal, which need not be finely divided, is placed in a porcelain dish covered with a watch-glass having a small hole at the edge through which a pipette may be introduced. 25 c.c. of nitric acid, sp. gr. 1\%2, are cautiously added, and, when the action has ceased, 5 c.c. of strong sulphuric acid are run in. The solution is evaporated until it solidifies, when water is added and the liquid filtered hot. The residue is washed with strong hydrochloric acid and water, then dried, ignited, and weighed. The silica is snow-white and granular. The results are generally a very little low, and the method has the advantages of rapidity and neatness. It is, however, not applicable with large percentages of silicon and manganese, both on account of the time taken in dissolving, and of the impurity of the residue. 


\section{Separation of Slag.}

The Chlorine Combustion Process.-This was originally suggested by Wöhler for the estimation of carbon in iron or steel, the metal being heated in a carrent of chlorine, whereby the iron is volatilised and the carbon left in a state fit for direct combustion in oxygen. Drown and Shimer, in their paper already cited, proposed the application of the process to the separation of silicon from titanium in iron, besides also estimating the carbon as above. Watts (Chem. News, 45, 279; Chem. Soc. J., Abstr., 42, 1134) subsequently essayed the estimation of carbon, and also the separation of silicon from the mechanically intermingled slag by a modification of the same method.

As proposed by Watts, the method of procedure was as follows :$B_{y}$ a snitable arrangement which he describes, a stream of chlorine is obtained, capable of being easily regulated at the will of the operator; the gas is then carefully dried by means of sulphuric acid, and is freed from air by passing it through a tube filled with lamp-black heated to redness. The iron, which may consist of borings or turnings, is weighed into a porcelain boat, and is introduced into a combustion tube, one end of which is bent at an angle of $110^{\circ}$, and dips into water contained in a flask. When the whole of the air has been expelled and the tube is filled with dry chlorine, it is heated to low redness in a furnace and the stream of gas maintained. The iron is volatilised as chloride and condenses in the cool part of the tube, while the silicon tetrachloride produced at the same time, being volatile, passes into the water and is decomposed. The water on evaporation yields silica, whilst the slag, mixed with carbon, remains unaltered in the boat. This method is stated to "enable the analyst to distinguish absolutely between the elemental and the oxidised portion of the silicon."

The above process appeared to possess such advantages that it was determined to adopt it, the only modifications at first introduced being the use of Ramsay's combustion-furnace, which worked very well, and allowed the whole apparatus to be placed within a moderatesized fume chamber, and so prevented the nuisance which might otherwise have been produced. All joints and stoppers were coated with paraffin and the leakage rendered quite trifling.

On working the process in this form, however, it was found to be attended with two very great disadvantages. In the first place, as shown by a subsequent table, there was a very considerable deficiency in the total amount of silicon found as compared with the results obtained by the processes mentioned in the early part of this paper; and secondly, the residue left in the boat, even after boiling with dilute hydrochloric acid before burning off the carbon, was found to 
contain variable and sometimes considerable amounts of substances other than slag.

The first and most obvious source of loss which presented itself was caused by the adherence of a perceptible quantity of silica to the extremity of the tube used for dipping into the water employed to decompose the silicon chloride, and it was found quite impossible to detach this completely, even by rubbing with a glass rod or the finger. To obviate this, a movable weighed tube was employed to dip into the water, and a considerable improvement was at once observed in the results. This is illustrated in the table given. It will be noticed, however, that the results were still slightly low, and this arose from the obstinate adhesion of a small quantity of silica to the sides of the flask employed, just above the level of the liquid. This was finally overcome by placing the water used for absorption of the silica in a weighed Varrentrapp's bulb. The following table shows the results obtained by the different modifications of the process :-

\begin{tabular}{|c|c|c|c|c|c|c|}
\hline \multirow[b]{2}{*}{ Original method $\ldots \ldots \ldots \ldots$} & \multicolumn{3}{|c|}{ Lileshall cold blast pig. } & \multicolumn{3}{|c|}{ Silicon pig. } \\
\hline & $\begin{array}{l}1 \cdot 17 \\
1 \cdot 11 \\
1 \cdot 34 \\
1 \cdot 11\end{array}$ & $\begin{array}{l}\text { ce } \\
", \\
"\end{array}$ & $\begin{array}{l}\mathrm{iO}_{2} . \\
" \\
" \\
"\end{array}$ & $\begin{array}{l}15 \cdot 31 \\
1533 \\
15 \cdot 75\end{array}$ & $\begin{array}{l}\text { cen } \\
" \\
"\end{array}$ & $\begin{array}{l}\mathrm{iO}_{2} . \\
" \\
"\end{array}$ \\
\hline With movable weighed tube \{ & $\begin{array}{l}2 \cdot 04 \\
2 \cdot 08 \\
2 \cdot 28 \\
2 \cdot 28\end{array}$ & $\begin{array}{l}" \\
" \\
"\end{array}$ & $\begin{array}{l}" \\
" \\
"\end{array}$ & $\begin{array}{l}18 \cdot 32 \\
18 \cdot 83\end{array}$ & $"$ & " \\
\hline $\left.\begin{array}{c}\text { With weighed Varrentrapp } \\
\text { bulb } \ldots \ldots \ldots \ldots \ldots \ldots \ldots\end{array}\right\}$ & $\begin{array}{l}2 \cdot 46 \\
2 \cdot 48\end{array}$ & $"$ & " & $\begin{array}{l}18 \cdot 86 \\
19 \cdot 17\end{array}$ & $"$ & $"$ \\
\hline
\end{tabular}

The above numbers show the actual $\mathrm{SiO}_{2}$ obtained, including that of the slag, calculated as percentage of iron taken. The amount of silicon is thus multiplied by $\frac{15}{7}$, and differences can be more easily noticed. It will be shown subsequently, in another table, that the latter numbers agree very fairly with the total silica obtained by other methods. The manner of procedure was then as follows.

The iron or steel, in large or small fragments, is placed in a porcelain boat and is burned in a stream of dry chlorine free from air. The excess of gas passing through the combustion-tube is washed by passing through water contained in a weighed Varrentrapp's bulb. When the combustion is completed, as indicated by the entire absence of red vapours near the boat, the current is maintained for 5 to 10 minutes, and the solution afterwards evaporated to dryness. The residue is extracted with hydrochloric acid to remove any iron, \&c., sometimes carried over, then filtered, washed, and ignited. 
The bulb is also weighed, after being carefully dried at $100^{\circ}$. These two weighings together furnish the whole of the unoxidised silicon originally present in the iron. The residue left behind in the boat contains carbon and slag, and also part of the manganese, a little iron as chloride, \&c. It may be most conveniently transferred to a testtube, boiled with a little dilute hydrochloric acid, filtered, dried, and ignited.

This residue often undoubtedly contains slag, sinee the small rounded pieces may be picked out and examined under the low power of a microscope, and qualitative analysis of the residne yields silica, iron, and calcium. It is, however, still contaminated to a variable extent with other substances, and in every case in which manganese was present in quantity in the original iron, it coald also be detected in this residue, which was at first believed to consist wholly of slag. Determinations of the amount of silica present in the residue from different analyses gave very variable results; for while in some cases it agreed very closely in composition with blast furnace slag, in others it showed very considerable differences. Thus blast furnace slag contains pretty uniformly about one-third of its weight of silica, and, while in some cases the silica in the residue varied between 30 and 39 per cent., yet in other cases only 18 per cent. was found, and, in one case, only 5 per cent. of silica was obtained. Further, the mean of ten determinations of slag, by the chlorine process, in Lileshall cold blast grey pig, gave 0.67 per cent., the numbers varying from 0.54 to 0.90 per cent., while two determinations in the same sample by Eggertz' bromine method gave only 0.27 and 0.32 per cent. of slag respectively. Hence it is necessary to estimate the silica present in the residue, by fusion in the ordinary way, before any trustworthy opinion can be formed as to the amount of slag present. When this is done, the results obtained by adding together the total silica found agree with those got by any other trust worthy method.

It may appear to all who have not actually worked the process, that in the form above recommended it must be troublesome and complicated, and there is doubtless some force in such an objection; but it must also be remembered that all methods of separating and estimating the slag are necessarily tedious. The process has been worked side by side with Eggertz' bromine method, and certainly has the advantage both in time and labour. The chief trouble is incurred in first setting up the apparatus, and in the occasional supply of frest: acid, drying tubes, manganese dioxide, \&c. But when the apparatus is once in order, a single analysis can be made in three hours, and, if many were required, the time might doubtless be shortened, and a number of analyses may be made with advantage without any attention being required by the apparatus. 
The operations are simple and readily performed, while, if Ramsay's burners are employed, and the combustion conducted in a fumechamber as recommended, no inconvenience is cansed in the laboratory, and, as compared with other methods, a considerable saving of time is effected.

The chlorine process appears also to lend itself especially to the rapid and correct determination of silicon in highly silicious pig-iron and in silicon ferromanganese. These varieties of metal burn quite readily in chlorine, and the amount of silicon being high, the experimental error, consequent upon numerous weighings, is much lessened.

In the table which follows is given the percentage of residue, consisting chiefly of silica obtained by the various processes before mentioned. Of the numbers referring to the chlorine process, the first line gives the total silica, while the last line gives the percentage of slag.

\begin{tabular}{|c|c|c|c|c|c|c|}
\hline & $\begin{array}{l}\text { Siemens- } \\
\text { Martin } \\
\text { mild } \\
\text { steel. }\end{array}$ & $\begin{array}{c}\text { Lileshall } \\
\text { cold } \\
\text { blast } \\
\text { grey pig. }\end{array}$ & $\begin{array}{c}\text { Denby } \\
\text { hot } \\
\text { blast } \\
\text { grey pig. }\end{array}$ & $\begin{array}{l}\text { S. Staf- } \\
\text { ford- } \\
\text { shire } \\
\text { No. } 1 \\
\text { grey pig. }\end{array}$ & $\begin{array}{l}\text { Welsh } \\
\text { silicon } \\
\text { ferro- } \\
\text { manga- } \\
\text { nese. }\end{array}$ & $\begin{array}{l}\text { Silicon, } \\
\text { pig. }\end{array}$ \\
\hline $\begin{array}{l}\text { I. With } \mathrm{HCl} \text {, and eva- } \\
\text { poration } \\
\text { II. With } \mathrm{HCl} \text {, without } \\
\text { evaporation } \\
\text { III. With } \mathrm{HCl} \text {, evapora- } \\
\text { tion and fusion }\end{array}$ & 0.04 & $\begin{array}{l}2 \cdot 53 \\
2 \cdot 51 \\
2 \cdot 37 \\
2 \cdot 37 \\
2 \cdot 58\end{array}$ & $6 \cdot 72$ & $14 \cdot 23$ & $22 \cdot 00$ & $20 \cdot 24$ \\
\hline $\begin{array}{c}\text { IV. With } \mathrm{HCI}+\mathrm{HNO}_{3} \text {, } \\
\text { and evaporation }\end{array}$ & 0.03 & $2 \cdot 45$ & $6 \cdot 21$ & $11 \cdot 40$ & $21 \cdot 56$ & $19 \cdot 23$ \\
\hline $\begin{array}{l}\text { V. Drown's method, } \\
\left(\mathrm{HNO}_{3}+\mathrm{H}_{2} \mathrm{SO}_{4}\right)\end{array}$ & 0.04 & $\begin{array}{l}2 \cdot 40 \\
2 \cdot 43\end{array}$ & $\begin{array}{l}6 \cdot 03 \\
6 \cdot 07\end{array}$ & $11 \cdot 42$ & $23 \cdot 32$ & $18 \cdot 79$ \\
\hline $\begin{array}{r}\text { Chlorine process, with } \\
\text { Varrentrapp bulb }\end{array}$ & $\begin{array}{l}0 \cdot 06 \\
0 \cdot 00\end{array}$ & $\begin{array}{l}2 \cdot 46 \\
0 \cdot 66\end{array}$ & $\begin{array}{l}6 \cdot 16 \\
0 \cdot 25\end{array}$ & $\begin{array}{r}11 \cdot 45 \\
0 \cdot 33\end{array}$ & $\begin{array}{r}21 \cdot 41 \\
0 \cdot 49\end{array}$ & $\begin{array}{r}19 \cdot 17 \\
0 \cdot 76\end{array}$ \\
\hline
\end{tabular}

It will be noticed that the amonnt of slag increases as the percentage of silicon becomes greater. The larger quantity present in the cold-blast pig may possibly be due to the lower temperature of the iron in the furnace during the separation of the slag.

In conclusion, from the above results and from the experiments mentioned earlier in the paper, I infer-

1. That methods I, III, IV, and V give fairly concordant results with steel and ordinary east iron, while of these four the method proposed by Drown has the advantages of most rapid action, least bulky residue, and most easily burned graphite.

2. That for silicon pig and silicon ferromanganese, methods I, II, 
and $V$ are quite inapplicable, while III and IV give moderately accurate results; but all these methods are incapable of distinguishing between oxidised and unoxidised silicon.

3. That the chlorine process, in the modified form above suggested, has the great advantage of distinguishing between the unoxidised silicon and slag, whilst it is rapid and fairly accurate with all classes of iron, and hence may help to supply a long-felt want of the iron and steel analyst. 